\title{
Aspirin induces IL-4 production: augmented IL-4 production in aspirin-exacerbated respiratory disease
}

\author{
Su-Kang Kong ${ }^{1}$, Byung Soo Kim ${ }^{1}$, Tae Gi Uhm², Hun Soo Chang ${ }^{3}$, Jong Sook Park ${ }^{4}$, Sung Woo Park ${ }^{4}$, \\ Choon-Sik Park ${ }^{4}$ and Il Yup Chung ${ }^{1,2}$
}

\begin{abstract}
Aspirin hypersensitivity is a hallmark of aspirin-exacerbated respiratory disease (AERD), a clinical syndrome characterized by the severe inflammation of the respiratory tract after ingestion of cyclooxygenase-1 inhibitors. We investigated the capacity of aspirin to induce interleukin-4 (IL-4) production in inflammatory cells relevant to AERD pathogenesis and examined the associated biochemical and molecular pathways. We also compared IL-4 production in peripheral blood mononuclear cells (PBMCs) from patients with AERD vs aspirin-tolerant asthma (ATA) upon exposure to aspirin. Aspirin induced IL-4 expression and activated the IL-4 promoter in a report assay. The capacity of aspirin to induce IL-4 expression correlated with its activity to activate mitogenactivated protein kinases, to form DNA-protein complexes on P elements in the IL-4 promoter and to synthesize nuclear factor of activated T cells, critical transcription factors for IL-4 transcription. Of clinical importance, aspirin upregulated IL-4 production twice as much in PBMCs from patients with AERD compared with PBMCs from patients with ATA. Our results suggest that IL-4 is an inflammatory component mediating intolerance reactions to aspirin, and thus is crucial for AERD pathogenesis. Experimental \& Molecular Medicine (2016) 48, e202; doi:10.1038/emm.2015.96; published online 8 January 2016
\end{abstract}

\section{INTRODUCTION}

Aspirin-exacerbated respiratory disease (AERD) refers to chronic rhinosinusitis, nasal polyposis and bronchoconstriction in asthmatics following the ingestion of aspirin or other cyclooxygenase-1 (COX-1) inhibitors. ${ }^{1}$ AERD is an acquired metabolic inflammatory disorder with adult onset that affects $\sim 10 \%$ of all patients with asthma. ${ }^{2,3}$ Aspirin hypersensitivity is the most specific marker for AERD and has aggressive airway manifestations, such as chronic rhinosinusitis, nasal polyps, frequent exacerbation and severe asthma. Moreover, the entire respiratory tract mucosa in patients with AERD is intensely infiltrated with eosinophils, mast cells and activated $\mathrm{T}$ cells. ${ }^{4-6}$ A distinguishing feature of AERD is the overproduction of and hyperreactivity to cysteinyl leukotrienes (CysLTs). The CysLT level is elevated both at baseline ${ }^{7}$ and following aspirin exposure in patients with AERD. ${ }^{8}$ Patients with AERD also express more $\mathrm{LTC}_{4}$ synthase ${ }^{9}$ and CysLT receptors on their inflammatory cells and respiratory tract mucosa compared with healthy controls. ${ }^{10}$ Platelet adherence to leukocytes has been implicated in excessive CysLT production in patients with AERD. ${ }^{11}$ In addition, inhibition of COX-1 decreases the production of inflammatory suppressive mediators such as prostaglandin E2 $\left(\mathrm{PGE}_{2}\right) .{ }^{12}$ AERD is therapeutically responsive to agents that block CysLT receptors or inhibit CysLT synthesis. ${ }^{13}$ Nonetheless, the precise role of CysLT overproduction/hyperreactivity in AERD has been questioned. Variable therapeutic responses have been observed among asthmatics treated with CysLT receptor 1 antagonists. ${ }^{14,15}$ Zileuton, a 5-lipoxygenase inhibitor, and montelukast and zafirlukast, inhibitors of CysLT receptor 1, are only partially effective at inhibiting the reaction to aspirin in patients with AERD. ${ }^{16-19}$ Moreover, their therapeutic effects may not even be related to aspirin hypersensitivity. ${ }^{20}$

Interleukin-4 (IL-4) is abundantly produced by a subset of leukocytes including T-helper type 2 cells, mast cells and eosinophils. ${ }^{21}$ Increased IL-4 levels have been found in the nasal mucosa of patients with chronic rhinosinusitis. ${ }^{6,22}$ IL-4 potentiates many pathophysiological features of AERD, including the upregulation of $\mathrm{LTC}_{4}$ synthase ${ }^{23}$ on mast cells and of CysLT receptors 1 and/or 2 on immune cells. ${ }^{24-27}$ IL-4 also induces vascular adhesion molecules to facilitate eosinophil extravasation, ${ }^{28}$ decreases $\mathrm{PGE}_{2}$ production by inhibiting

\footnotetext{
${ }^{1}$ Department of Bionano Technology, Hanyang University, Ansan, Republic of Korea; ${ }^{2}$ Department of Molecular and Life Sciences, College of Science and Technology, Hanyang University, Ansan, Republic of Korea; ${ }^{3}$ Soonchunhyang Medical Science Research Institute, College of Medicine, Soonchunhyang University, 22, Soonchunhyang-ro, Asan, Chungcheongnam-do, Republic of Korea and ${ }^{4}$ Division of Allergy and Respiratory, Department of Internal Medicine, Soonchunhyang University Bucheon Hospital, Gyeonggi-do, Republic of Korea

Correspondence: Professor IY Chung, Department of Bionano Technology, Hanyang University, 1271 Sa-1-dong, Ansan, Gyeonggi-do 426-791, Republic of Korea.
}

E-mail: iychu@hanyang.ac.kr

Received 27 July 2015; accepted 11 September 2015 
COX-2 and microsomal $\mathrm{PGE}_{2}{ }^{27}$ and activates T-helper type 2 differentiation and inflammation. ${ }^{29}$ Thus, IL-4 is an important mediator of the AERD phenotype.

Aspirin is believed to exert its anti-inflammatory effect, which has typically been evaluated in the presence of potent proinflammatory mediators such as phorbol myristate acetate, calcium ionophores, cytokines and LPS. ${ }^{30-33}$ In these conditions, the anti-inflammatory effects of aspirin are shown to be mediated by the inhibition of $\mathrm{PGE}_{2}$ synthesis and other inflammatory signaling molecules ${ }^{34}$ such as NF- $\mathrm{\kappa B}$ (nuclear factor- $\mathrm{kB}$ ), ${ }^{30} \mathrm{AP}-1$ (activator protein-1), ${ }^{35}$ ERK1/2 (extracellular signal-regulated kinase $1 / 2)^{36}$ and STAT6 (signal transducer and activator of transcription 6). ${ }^{31,32}$ These effects appear to be independent of COX inhibition. Moreover, aspirin has been reported to inhibit $I L-4$ transcription in activated $\mathrm{CD} 4^{+} \mathrm{T}$ cells via an unknown mechanism. ${ }^{33}$ Aspirin-mediated inhibition of IL-4 synthesis has been hypothesized to explain the therapeutic benefit of aspirin desensitization treatment. ${ }^{37}$ However, the effect of aspirin itself on inflammatory responses in the absence of inflammatory stimuli has rarely been evaluated. We previously demonstrated that aspirin stimulates $I L-4$ transcription in some leukemic cell lines. ${ }^{38}$ This result was surprising, as aspirin-induced IL-4 expression is in sharp contrast to the reported inhibitory effect on IL-4 production. ${ }^{33}$ However, our results may provide an important perspective on aspirin hypersensitivity, given the multifaceted roles of IL-4 in generating the pathophysiological characteristics of AERD, a T-helper type 2-type disease. In the present study, we investigated whether aspirin induced IL-4 production and examined the associated biochemical and molecular mechanisms. We also found that peripheral blood mononuclear cells (PBMCs) from patients with AERD produce more IL-4 upon exposure to aspirin compared with those from patients with aspirin-tolerant asthma (ATA).

\section{MATERIALS AND METHODS}

\section{Cell cultures}

HMC-1, EoL-1, Jurkat and human cord blood (CB) eosinophils and mast cells were cultured as described previously. ${ }^{39,40}$ The identity of $\mathrm{CB}$ eosinophils was confirmed by intracellular staining with antihuman MBP antibody (BD Pharmingen, San Diego, CA, USA), which indicated $>90 \%$ purity. The purity of the CB mast cells was also $>90 \%$, as determined by staining with anti-human FceRI $\alpha$ (Millipore, Bedford, MA, USA). The PBMCs were isolated using Ficoll-Paque Premium 1.073 (GE Healthcare, Uppsala, Sweden).

\section{Measurement of IL-4 mRNA expression}

The cells were treated with aspirin (A2093) or celecoxib (PZ0008) from Sigma-Aldrich (St Louis, MO, USA) for the indicated time intervals. cDNA synthesis from total RNA and quantitative real-time PCR (qPCR) were performed as described previously. ${ }^{39}$ The $I L-4$ mRNA levels were normalized to the PP1A mRNA levels. The relative expression was evaluated using the comparative cycle threshold $\left(2^{-\Delta \Delta C t}\right)$ method. The mean normalized gene expression \pm s.e.m. was calculated from independent experiments. The following primers were used: $I L-4$-forward, 5'-AACAGCCTCACAGAGCAGAAGAC-3'; reverse, 5'-GCCCTGCAGAAGGTTTCCTT-3'; PP1A-forward,
5'-TCCTGGCATCTTGTCCATG-3'; reverse, 5'-CCATCCAACCACT CAGTCTTG- $3^{\prime}$. The PCR product of the $I L-4$ gene was confirmed by sequencing.

\section{Flow cytometry}

The cells were fixed in $4 \%$ paraformaldehyde (Sigma-Aldrich) for $15 \mathrm{~min}$ at $4{ }^{\circ} \mathrm{C}$, stained intracellularly with either phycoerythrinconjugated mouse anti-human IL-4 monoclonal antibodies (mAbs) (BioLegend, San Diego, CA, USA) or mouse IgG1 Abs (BD Pharmingen), and analyzed with a FACSCalibur flow cytometer and CellQuest software (Becton Dickinson, San Jose, CA, USA).

\section{Western blot analysis}

Cell lysates were prepared in RIPA buffer as described previously. ${ }^{39}$ The blots were probed with anti-phospho-ERK1/2, anti-ERK, antiphospho-p38, anti-p38, anti-phospho-JNK (c-Jun N-terminal kinase) and anti-JNK Abs (Cell Signaling Technology, Beverly, MA, USA). Expression of nuclear factor of activated T cells (NFAT), which has a crucial role in immune function, was monitored with anti-NFAT1 and anti-NFAT2 Abs (Abcam, Cambridge, UK). The blots were probed with anti-glyceraldehyde 3-phosphate dehydrogenase Abs (Santa Cruz Biotechnology, Santa Cruz, CA, USA) as a loading control. Secondary anti-rabbit horse radish peroxidase-conjugated Abs and anti-mouse horse radish peroxidase-conjugated Abs were obtained from Cell Signaling Technology. Immunoreactive bands were visualized using an ECL detection system (Amersham Biosciences, Buckinghamshire, UK).

\section{Luciferase reporter assay}

The luciferase reporter vector consisting of the $I L-4$ promoter sequence (from -649 to -1 relative to the translation start site) subcloned into pGL3-Basic (Promega, Madison, WI, USA) has been described previously. ${ }^{38}$ IL-4 promoter deletion constructs were generated by PCR using the primers listed in Supplementary Table S1. Transfection was performed with Lipofectamine 2000 (Invitrogen Life Technologies, Waltham, MA, USA) for HMC-1 cells and Jurkat cells or with an Amaxa 4D-nucleofector (Lonza, Köln, Germany) for EoL-1 cells. The luciferase activity was measured and expressed as described previously. ${ }^{39}$

\section{Nuclear extract preparation and EMSA}

Nuclear extracts were subjected to electrophoretic mobility shift assay (EMSA) analysis as described previously, ${ }^{39}$ using probes for six $\mathrm{P}$ elements $^{41}$ and for an aspirin-targeted region (ATR), which was previously implicated in the aspirin-induced inhibition of IL-4 production in activated T cells. ${ }^{33}$ The ATR extends from nucleotides -164 to -200 in the $I L-4$ promoter. For supershift analysis, the extracts were incubated with anti-NFAT Abs or control Abs (Sigma-Aldrich) before reaction with the radiolabeled P4 probe.

\section{Subjects}

Written informed consent was obtained from all subjects. The protocols used in this study were approved by the Ethics Committees of Hanyang University (HYG-11-019-1), Soonchunhyang University Bucheon Hospital (SCHBC_IRB_05_02 and schbc-biobank-2012-004) and the Korean Red Cross, Korea. Patients with AERD $(n=11)$ or ATA $(n=12)$ were recruited from the outpatient clinics of Soonchunhyang University Bucheon Hospital. All patients were diagnosed by physicians and met the definition of asthma from the Global Initiative for Asthma guidelines. ${ }^{42}$ Questionnaires covered the five specific elements of aspirin hypersensitivity (dyspnea, wheezing, 
nasal blockage, skin eruption and loss of consciousness after aspirin ingestion). To confirm aspirin hypersensitivity, oral aspirin challenges with increasing doses of aspirin were performed with all asthmatics as described. ${ }^{43,44}$ The oral aspirin challenge reactions were categorized into two groups: a $15 \%$ or greater decrease of forced expiratory volume in $1 \mathrm{~s}$ or the appearance of naso-ocular reactions (AERD) and a decrease of $<15 \%$ of forced expiratory volume in $1 \mathrm{~s} 1$ without naso-ocular or cutaneous reactions (ATA). The clinical characteristics of the AERD and ATA groups are compared in Table 1. Blood samples for the control subjects were provided by the Korean Red Cross. These subjects had no history of drug allergy, including aspirin hypersensitivity. Therefore, the clinical parameters were considered not be to be applicable because no measurement of these parameters was made.

\section{Statistical analysis}

All statistical analyses were performed using SPSS software, version 12.0 (SPSS, Chicago, IL, USA). Independent $t$-test was used to compare the relative reporter activities between the experiments. The Kruskal-Wallis and post hoc Mann-Whitney tests were used to analyze the differences between the $I L-4$ mRNA levels in PBMCs in the control, ATA and AERD groups. Differences with a $P$-value $<0.05$ were considered statistically significant. The results are expressed as the means \pm s.e.m.

\section{RESULTS}

\section{Aspirin-mediated induction of IL-4 mRNA expression and} protein production

We first examined whether primary cells, including PBMCs, CB eosinophils and CB mast cells, expressed IL-4 in response to aspirin. Aspirin induced $I L-4 \mathrm{mRNA}$ in a dose-dependent manner (Figure 1). Next, we examined IL-4 expression in HMC-1 mast cells, EoL-1 eosinophilic cells and Jurkat T cells, which were chosen because they are representative of cells that express high levels of IL-4 in vivo ${ }^{21}$ and are relevant to AERD pathogenesis. ${ }^{4-6}$ Aspirin induced a similar, dose-dependent

Table 1 Clinical characteristics of the study subjects

\begin{tabular}{|c|c|c|c|}
\hline & ATA & $A E R D$ & P-value \\
\hline$N$ & 12 & 11 & - \\
\hline Age $\left(\right.$ years) ${ }^{b}$ & $53.4 \pm 14.0$ & $42.6 \pm 14.8$ & 0.089 \\
\hline Gender (male, \%) & 27.3 & 25.0 & 0.901 \\
\hline $\begin{array}{l}\text { Smoking status } \\
\text { (smoker, \%) }\end{array}$ & 9.1 & 8.3 & 0.865 \\
\hline Height $(\mathrm{cm})^{\mathrm{b}}$ & $159.6 \pm 10.3$ & $164.0 \pm 10.4$ & 0.317 \\
\hline Weight $(k g)^{b}$ & $63.6 \pm 9.1$ & $63.6 \pm 11.4$ & 0.990 \\
\hline Body mass index $\left(\mathrm{kg} \mathrm{m}^{-2}\right)^{b}$ & $25.0 \pm 2.5$ & $23.7 \pm 3.7$ & 0.354 \\
\hline $\begin{array}{l}\text { Decline in } \mathrm{FEV} 1 \text { by aspirin } \\
\text { provocation }(\%)^{\mathrm{b}}\end{array}$ & $5.3 \pm 5.3$ & $26.5 \pm 8.0$ & $<0.001$ \\
\hline Blood eosinophils $(\%)^{b}$ & $8.3 \pm 17.4$ & $6.8 \pm 4.7$ & 0.785 \\
\hline FEV1 $(\% \text { predicted })^{\mathrm{b}}$ & $87.7 \pm 14.6$ & $84.7 \pm 29.3$ & 0.760 \\
\hline $\begin{array}{l}\text { PC20 methacholine } \\
\left(\mathrm{mg} \mathrm{ml}^{-1}\right)^{\mathrm{b}}\end{array}$ & $11.0 \pm 11.1$ & $5.5 \pm 7.6$ & 0.218 \\
\hline Total lgE $\left(I U \mathrm{ml}^{-1}\right)^{\mathrm{b}}$ & $175.0 \pm 279.7$ & $391.3 \pm 463.2$ & 0.191 \\
\hline Skin test (positive, \%) & 54.5 & 50.0 & 0.827 \\
\hline
\end{tabular}

Abbreviations: AERD, aspirin-exacerbated respiratory disease; ATA, aspirin-tolerant asthma; FEV1, forced expiratory volume in $1 \mathrm{~s}$; Ig, immunoglobulin.

aThe $P$-values were obtained using $\chi^{2}$ test and independent $t$-test.

bPresented as mean + s.d. pattern of $I L-4$ transcription in each cell line (Figure 2a). Kinetic experiments showed that $I L-4$ expression reached a peak $2-4 \mathrm{~h}$ after stimulation and declined thereafter (Figure 2b). Aspirin also activated the $I L-4$ promoter in all three cell lines (Figure 2c). The intracellular IL-4 protein levels also increased in a dose-dependent manner upon exposure to aspirin for $24 \mathrm{~h}$ (Figure 2d). No cytotoxic effects of $0.2-5 \mathrm{~mm}$ aspirin were observed in any of these cells for the indicated period of time, as evaluated by Trypan blue exclusion. Celecoxib, a selective COX-2 inhibitor, ${ }^{3}$ which has no
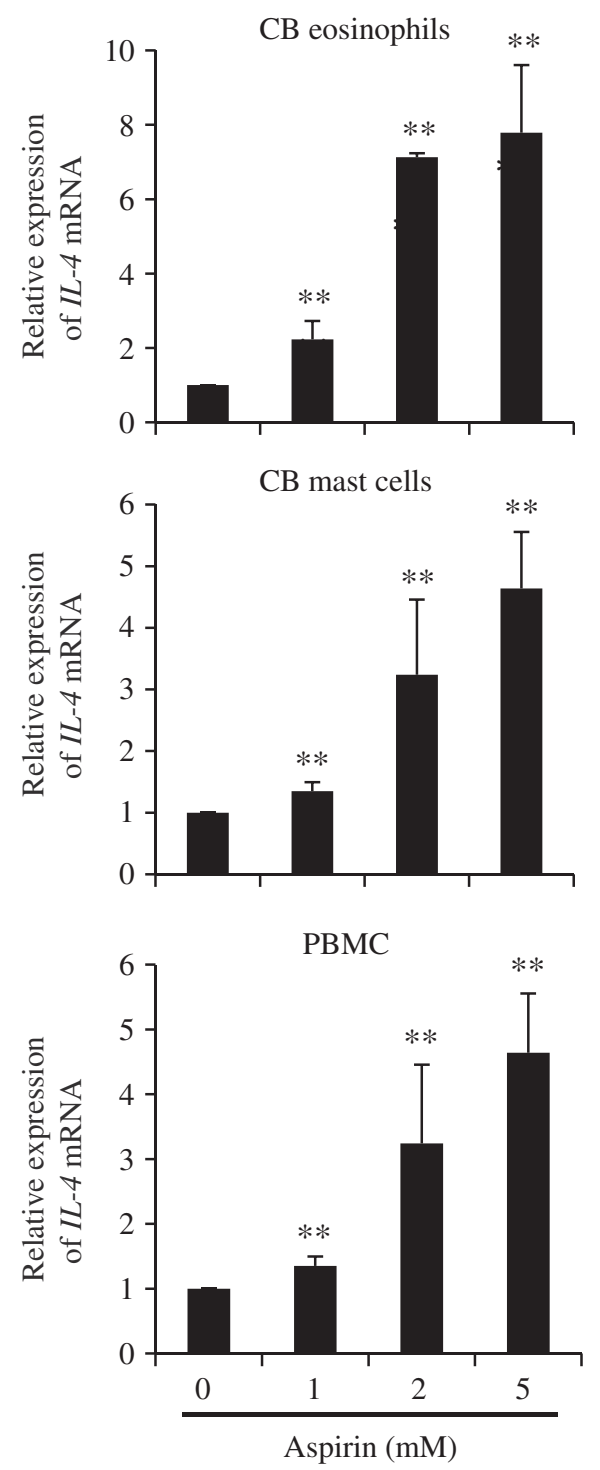

Figure 1 Aspirin induces interleukin-4 (IL-4) mRNA expression in cord blood (CB) eosinophils, $\mathrm{CB}$ mast cells and peripheral blood mononuclear cells (PBMCs). $C B$ eosinophils and $C B$ mast cells were differentiated from $\mathrm{CD}_{3} 4^{+} \mathrm{CB}$ cells for 24 and 42 days, respectively. PBMCs were isolated from normal subjects. The cells were treated with aspirin for $4 \mathrm{~h}$, and IL-4 mRNA expression was measured by quantitative real-time PCR (qPCR). The data are presented as the mean \pm s.e.m. for eosinophils $(n=3)$, mast cells $(n=3)$ and PBMCs $\left(n=6 ;{ }^{*} P<0.01\right.$ compared with unstimulated cells at $4 \mathrm{~h}$ ). 

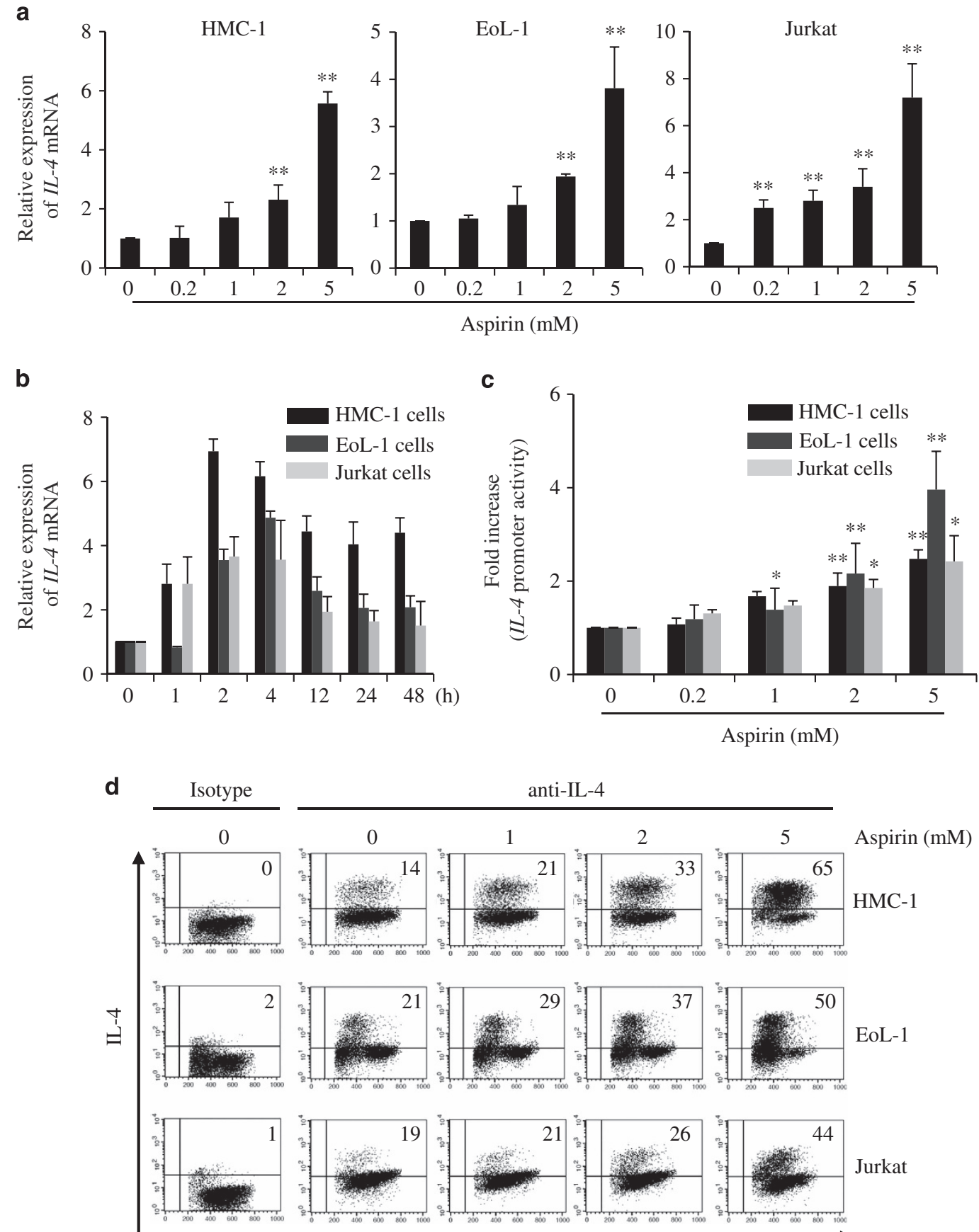
Aspirin (mM)
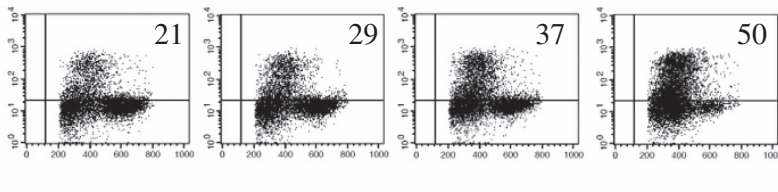

EoL-1
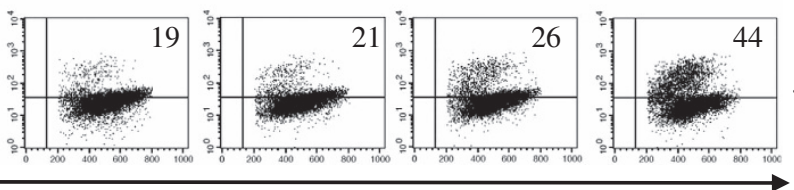

FSC

Figure 2 Aspirin induces interleukin-4 (IL-4) mRNA expression and protein production. (a) HMC-1, EoL-1 and Jurkat cells were treated with various concentrations of aspirin for $4 \mathrm{~h}$. IL-4 expression was measured by quantitative real-time PCR (qPCR); $n=4-6$. The IL-4 mRNA levels (means \pm s.e.m.) are expressed relative to the $P P 1 A$ expression levels ( $* * P<0.01$ compared with unstimulated cells at $4 \mathrm{~h}$ ). (b) Kinetics of $I L-4$ expression in the presence of $5 \mathrm{~mm}$ aspirin; $n=2$. (c) Cells were transfected with an $I L-4$ promoter reporter (-649). After $24 \mathrm{~h}$, the transfected cells were stimulated with aspirin for $4 \mathrm{~h} ; n=4\left({ }^{*} P<0.05\right.$ and ${ }^{*} P<0.01$ compared with unstimulated cells at $4 \mathrm{~h}$ ). (d) Cells were treated with aspirin for $24 \mathrm{~h}$, and the levels of intracellular IL-4 were analyzed by FACS (fluorescence activated cell sorting).

crossreactivity with aspirin and thus is tolerated, ${ }^{1,3}$ did not induce IL-4 expression at concentrations within or above its respective COX-inhibitory range $(1-100 \mu \mathrm{M})^{45}$ in any cell type examined (Supplementary Figure S1). In summary, aspirin induced IL-4 production in all of the cell types examined.

\section{Activation of ERK, p38 and JNK in aspirin-induced IL-4}

\section{expression}

Aspirin can activate, inhibit or have no effect on mitogenactivated protein kinase (MAPK) family members. ${ }^{34}$ Thus, we examined the effects of aspirin on various MAPK family 

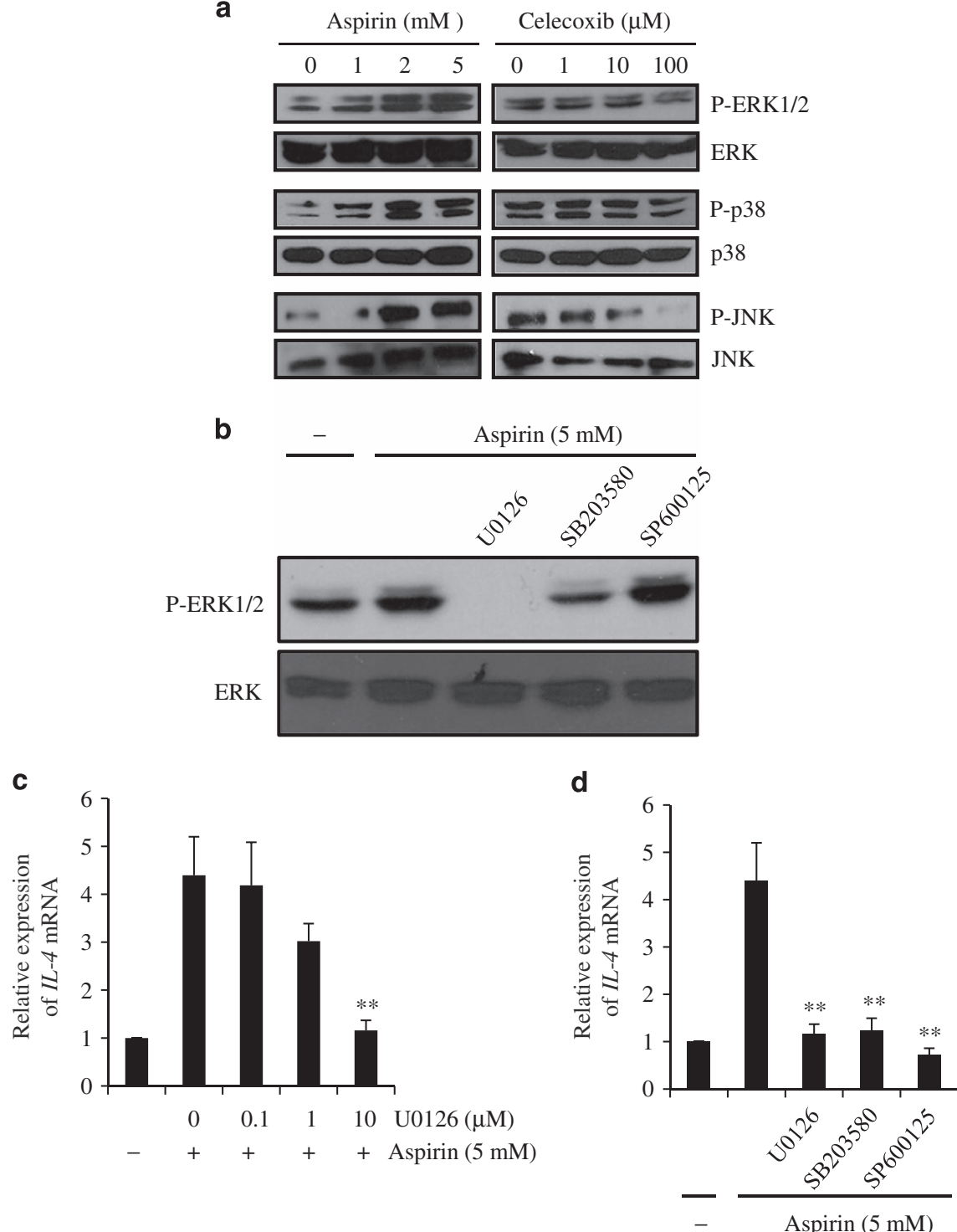

Figure 3 Interleukin (IL-4) mRNA expression requires the activation of mitogen-activated protein kinases (MAPKs). (a) HMC-1 cells were treated with aspirin or celecoxib for $4 \mathrm{~h}$. Activation of MAPKs was then assessed by western blotting. The blots were probed with antiphospho-MAPK antibodies (Abs). Replica blots were probed for total MAPKs as loading controls. (b) HMC-1 cells were treated with aspirin $(5 \mathrm{~mm})$ for $4 \mathrm{~h}$ following pretreatment with U0126 (10 $\mu \mathrm{m})$, SB203580 (10 $\mu \mathrm{m})$ or SP600125 (20 $\mu \mathrm{m})$ for 30 min. The blots were probed with anti-phospho-ERK1/2 Ab and reprobed with anti-total ERK Ab as a loading control. (c) HMC-1 cells were treated with aspirin (5 mm) for $4 \mathrm{~h}$ following pretreatment with increasing doses of U0126 or for $30 \mathrm{~min}$. IL-4 expression was then assessed by quantitative real-time

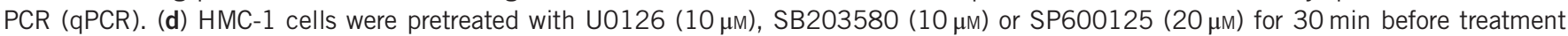
with aspirin for $4 \mathrm{~h}$. IL-4 expression was then quantified by qPCR. The data (mean \pm s.e.m., $n=3$ ) are expressed relative to the $P P 1 A$ mRNA levels $\left({ }^{*} P<0.01\right.$ compared with aspirin-treated cells). ERK1/2, extracellular signal-regulated kinase 1/2; JNK, c-Jun N-terminal kinase.

members. The treatment of HMC-1 cells with aspirin for $4 \mathrm{~h}$ resulted in a dose-dependent activation of ERK1/2 (Figure 3a). Aspirin at 5-20 mm concentrations has been shown to inhibit ERK1/2 activation in cells under stress conditions. ${ }^{46,47}$ Because the latter observation conflicted with our findings, we used U0126, an ERK inhibitor. In the presence of U0126, ERK1/2 phosphorylation (Figure $3 \mathrm{~b}$ ) and $I L-4$ mRNA levels (Figure $3 \mathrm{c}$ ) were decreased. Moreover, phospho-p38 and phospho-JNK levels were elevated with increased concentrations of aspirin, and the inhibitors of these two MAPKs almost completely blocked IL-4 transcription in a dose-dependent manner (Figure 3d). In contrast, celecoxib did not activate ERK1/2 or p38; in fact, the compound reduced JNK phosphorylation at high doses (Figure 3a). These results indicate that activation of each MAPK member is necessary for aspirin-induced IL-4 expression.

\section{Aspirin responsiveness does not map to any particular region within the $I L-4$ proximal promoter}

We next investigated which cis-acting elements or sequences within the $I L-4$ promoter are aspirin-responsive. At least six $\mathrm{P}$ 
a

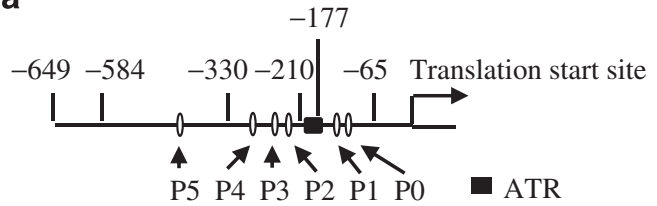

b
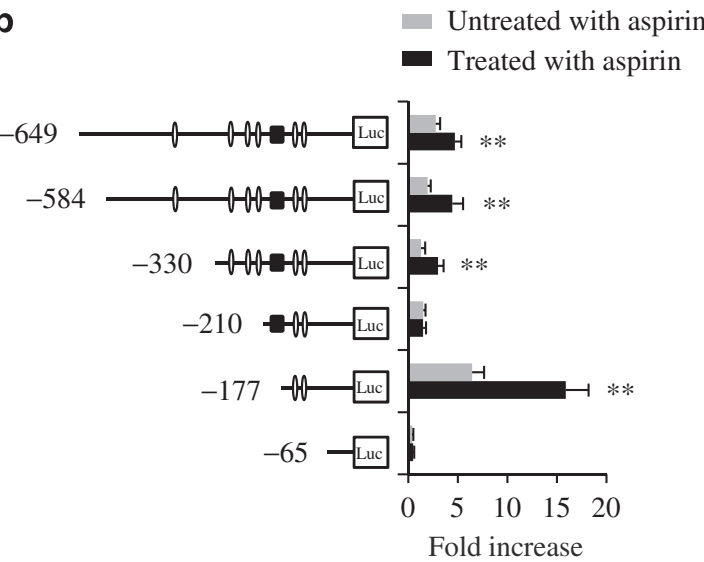

(IL-4 promoter activity)

Figure 4 Aspirin augments interleukin (IL-4) promoter activity. (a) The IL-4 proximal promoter. (b) HMC-1 cells were transfected with reporter constructs. After $24 \mathrm{~h}$, the cells were stimulated with aspirin $(5 \mathrm{~mm})$ for an additional $4 \mathrm{~h}$. Reporter activity was then analyzed. The data (mean \pm s.e.m., $n=3$ ) are presented as fold increase compared with unstimulated cells $(* * P<0.01$ compared with unstimulated cells). ATR, aspirin-targeted region.

elements (P0-P5) and other sequence elements in the IL-4 proximal promoter have been shown to have a critical role in IL-4 transcriptional activation. ${ }^{48}$ NFAT binds to most, if not all, $\mathrm{P}$ elements through interactions with $\mathrm{AP}-1^{41}$ or other transcription factors. ${ }^{49}$ To study the responsiveness of the $\mathrm{P}$ elements, serially deleted $I L-4$ promoter reporters were constructed (Figure 4a). HMC-1 cells were transfected with these constructs and then treated with aspirin. Aspirin responsiveness was well conserved in the three largest constructs $(-649,-584$ and -330$)$, which retained all or most of the P elements. The -210 promoter reporter, which lacked the P5, P4 and P3 elements, was no longer aspirin-responsive. The -177 construct, which lacked two-thirds of the ATR but contained the P0 and P1 elements, retained aspirin responsiveness (Figure 4b). Identical response patterns were observed in Jurkat and EoL-1 cells (data not shown). These results suggest that the aspirin-responsive sequence of the $I L-4$ proximal promoter is not confined to a particular region.

\section{Aspirin alters DNA-protein complex formation at the IL-4 proximal promoter}

HMC-1 cells were treated with aspirin or celecoxib for $4 \mathrm{~h}$. Nuclear extracts were generated and subjected to EMSA analysis. In unstimulated cells, few or no protein complexes were formed with the $\mathrm{P} 0, \mathrm{P} 2$ and ATR probes. In contrast, the P1, P3, P4 and P5 probes all bound to protein(s) (Figure 5a). The treatment of HMC-1 cells with aspirin resulted in a slightly increased amount of DNA-protein complexes with the P0, P2 a
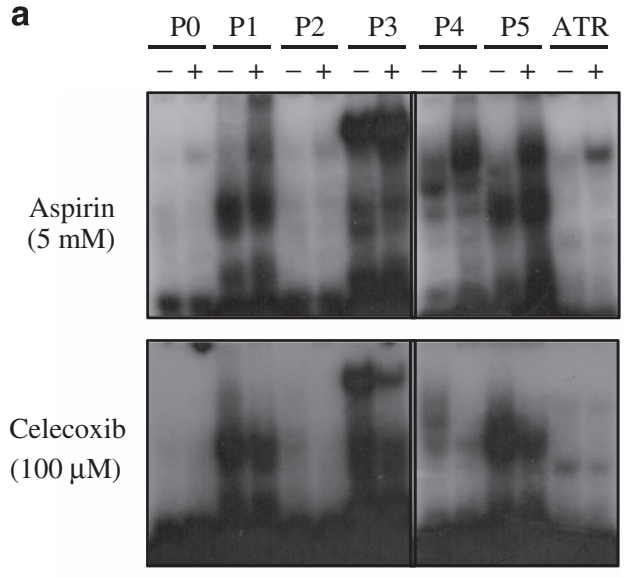

b

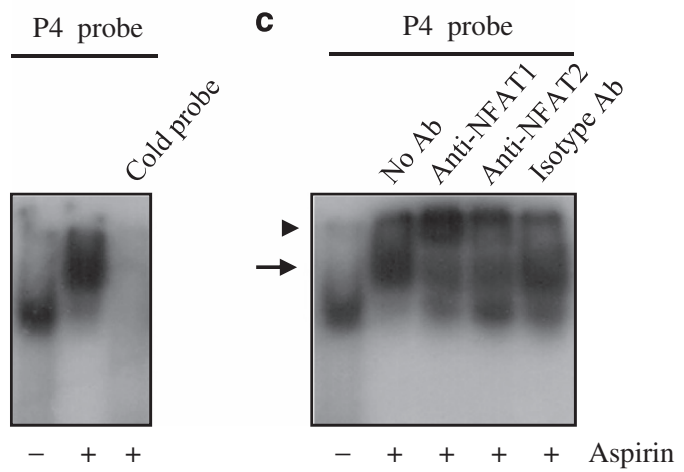

Figure 5 Aspirin induces the formation of DNA-protein complexes on $\mathrm{P}$ elements in the interleukin-4 (IL-4) promoter. (a) HMC-1 cells were treated with aspirin or celecoxib for $4 \mathrm{~h}$. Nuclear extracts were incubated with ${ }^{32}$ P-labeled oligonucleotides, as indicated. Representative results are shown $(n=3)$. (b) Nuclear extracts from aspirin-treated HMC-1 cells were incubated with the ${ }^{32} \mathrm{P}$-labeled P4 probe in the presence or absence of its cold probe. (c) Nuclear extracts from aspirin-treated HMC-1 cells were incubated with the ${ }^{32}$ P-labeled P4 probe following reaction with anti-NFAT1, antiNFAT2 or isotype-control antibodies (Abs). The arrow and the arrowhead indicate the major DNA-protein complex and the supershifted band, respectively. ATR, aspirin-targeted region; NFAT, nuclear factor of activated T cell.

and ATR probes and a substantial increase with the P1 and P3 probes. Moreover, a slower-migrating species appeared with the P4 and P5 probes. Each cold probe efficiently outcompeted the augmented or newly formed DNA-protein complexes (data not shown), indicating that these bands are specific. In contrast, celecoxib failed to induce DNA-protein complex formation with the P0, P1, P2 or ATR probes. Furthermore, this compound considerably reduced DNA-protein complex formation with the P3, P4 and P5 probes.

\section{Synthesis of NFATs by aspirin and celecoxib}

NFAT1 and NFAT2 are both required for IL-4 expression in T cells. ${ }^{50}$ Treatment of HMC- 1 cells for $4 \mathrm{~h}$ with aspirin, but not celecoxib, stimulated NFAT1 and NFAT2 production (Figure 6). EMSA analysis showed that the P4-protein complex that disappeared following treatment with a $\mathrm{P} 4$ cold probe (Figure 5b) and was increased by aspirin treatment was 


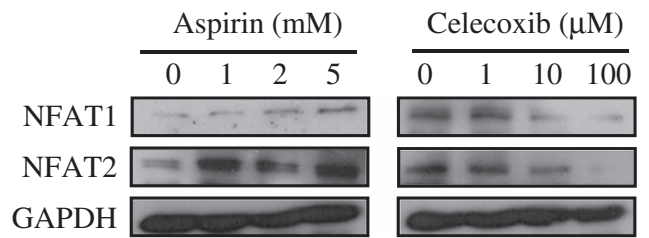

Figure 6 Aspirin induces the synthesis of nuclear factor of activated T cells (NFATs). HMC-1 cells were treated with aspirin or celecoxib for $4 \mathrm{~h}$. The levels of NFAT1 and NFAT2 were then analyzed by western blotting. Images are representative of three independent experiments. GAPDH, glyceraldehyde 3-phosphate dehydrogenase.

supershifted by incubation with anti-NFAT1 or anti-NFAT2 Abs but not with isotype-control Abs (Figure 5c). This result indicates that aspirin induces IL-4 expression at least, in part, through the increased synthesis of NFATs. This conclusion is also supported by a collection of the IL-4 promoter deletion experiments, the formation of DNA-protein complex and the upregulation of NFAT synthesis. The -330 or longer constructs, all of which contain most P elements, were aspirinresponsive. This could be because aspirin increased or induced the formation of the DNA-protein complexes, presumably including NFAT1 or NFAT2, on these elements. The -210 construct, which contains P0, P1 and the ATR, was not aspirinresponsive (Figure 4). In this construct, the ATR represses IL-4 expression in a dominant manner, despite the presence of P1, which appears to act as a positive element. Finally, the -177 construct, which contains P0 and P1 but lacks the ATR, restored the aspirin response because of the presence of $\mathrm{P} 1$, which has previously been shown to interact with NFAT1 and NFAT2. ${ }^{51}$ Thus, both $\mathrm{P}$ elements and the ATR appear to regulate the aspirin-mediated expression of IL-4.

\section{The effects of aspirin on IL-4 expression in PBMCs from patients with AERD or ATA}

We next examined IL-4 expression in PBMCs from patients with AERD or ATA (Table 1). Aspirin upregulated IL-4 expression in PBMCs from both groups compared with the untreated controls. Of particular note, aspirin upregulated $I L-4$ mRNA expression twice as much in PBMCs from patients with AERD compared with those from patients with ATA $(4.50 \pm 0.32, \quad n=11 \quad$ vs $2.25 \pm 0.18, \quad n=12$, respectively; $P=0.00004)$, as seen in Figure 7a. In contrast, celecoxib did not upregulate IL-4 expression in any group. Aspirin, also induced IL-4 expression in PBMCs from control subjects (Figure 7a). The fold induction in control PBMCs $(1.94 \pm 0.17)$ was significantly lower compared with that in PBMCs from patients with AERD $(P=0.00003)$ but was comparable with that in the PBMCs of patients with ATA (Figure 7a). Similarly, a significantly higher IL-4 protein expression was observed in aspirin-treated PBMCs from AERD patients compared with that in ATA patients $(P=0.0002$; Figure $7 b)$.
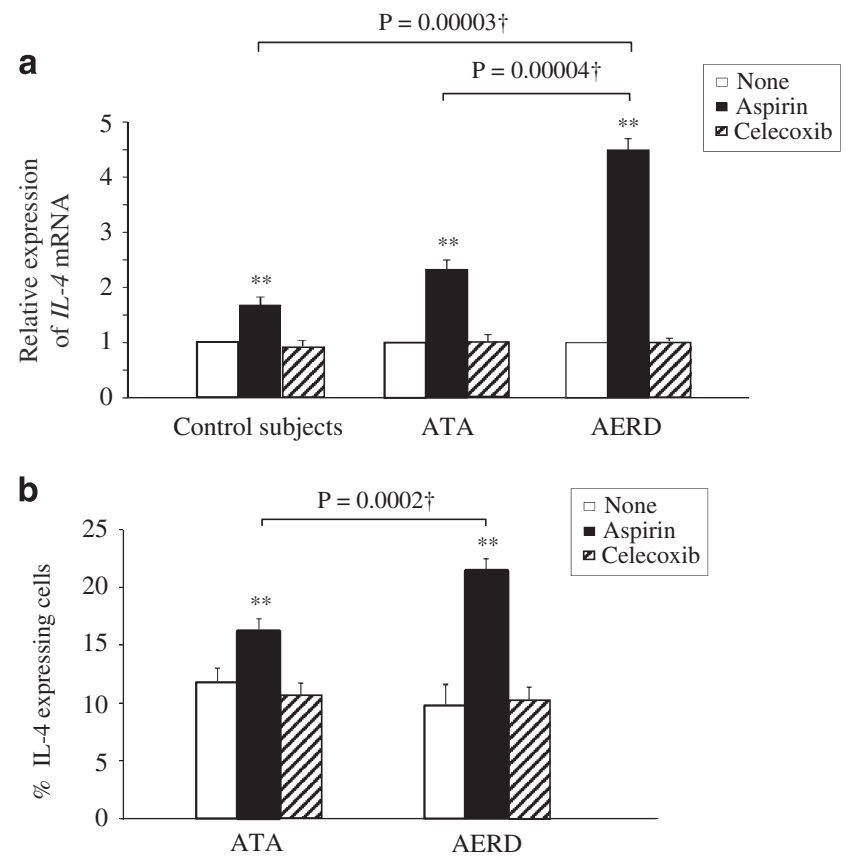

Figure 7 Aspirin upregulates interleukin-4 (IL-4) production to a greater extent in peripheral blood mononuclear cells (PBMCs) from patients with aspirin-exacerbated respiratory disease (AERD) compared with those from patients with aspirin-tolerant asthma (ATA). (a) PBMCs were treated with aspirin $(5 \mathrm{~mm})$ or celecoxib $(100 \mu \mathrm{m})$ for $4 \mathrm{~h}$. IL-4 expression was then measured by quantitative real-time PCR (qPCR). The data are presented as the mean \pm s.e.m. (patients with AERD, $n=11$; patients with ATA, $n=12$; control subjects, $n=8 ;{ }^{* *} P<0.01$ compared with unstimulated cells within each group at $4 \mathrm{~h}$ ). (b) PBMCs were treated with the two compounds for $24 \mathrm{~h}$, and the levels of intracellular IL-4 were analyzed by FACS (fluorescence activated cell sorting). The data are presented as the mean \pm s.e.m. (patients with AERD, $n=11$; patients with ATA, $n=12 ;{ }^{* *} P<0.01$ compared with unstimulated cells within each group at $4 \mathrm{~h}$ ). tComparisons of aspirin-treated PBMCs from patients with AERD vs patients with ATA.

\section{DISCUSSION}

The primary mechanism of AERD pathogenesis is believed to be the aspirin-mediated relief of negative inhibition of CysLT production. However, agents that modify or blunt CysLT metabolism partially eliminate respiratory reactions in patients with AERD, ${ }^{14-19}$ suggesting alternative and/or complementary pathways driving AERD pathogenesis. IL-4 potentiates many pathophysiological aspects of AERD. ${ }^{6,22-29}$ We have previously demonstrated that aspirin induces $I L-4$ transcription in some leukemic cells, ${ }^{38}$ raising the possibility that IL-4 is an inflammatory mediator of aspirin hypersensitivity. This observation is intriguing considering that AERD is considered to be a T-helper type 2-mediated disorder. The present study indicates that aspirin is directly linked with IL-4 production in the context of AERD pathogenesis as (i) aspirin induced IL-4 expression and activated the IL-4 promoter in cell types relevant to AERD pathogenesis, indicating that IL-4 may be a direct target of aspirin; (ii) aspirin-induced IL-4 production was accompanied by the activation of biochemical and 
molecular pathways leading to $I L-4$ transcription; (iii) aspirininduced higher levels of IL-4 transcription in PBMCs from patients with AERD compared with those from patients with ATA. Based on these results, we suggest that IL-4 serves as an important inflammatory mediator for intolerance reactions to aspirin.

The aim of the present study is threefold: to examine aspirin-induced IL-4 production, to analyze its biochemical and molecular mechanisms and to corroborate the differential response to aspirin by comparing IL-4 production in primary cells from patients with AERD and ATA. We used both human leukemic cell lines and their primary counterparts, which are more relevant to the pathogenesis of aspirin sensitivity. We found that aspirin induced IL-4 expression in nearly all of the cells examined, whereas celecoxib did not. Their ability or inability to induce IL-4 expression was consistent with their ability to activate the three MAPK members, form DNA-protein complexes with $\mathrm{P}$ elements and the ATR in the IL-4 promoter, and upregulate production of NFATs, which are critical transcription factors for $I L-4 .^{48}$ EMSA analysis showed that the DNA-protein complexes included both NFAT1 and NFAT2. Notably, aspirin itself has been shown to increase intracellular $\mathrm{Ca}^{2+}$ levels, transiently upregulate protein kinase $\mathrm{C}$ in $\mathrm{T}$ cells ${ }^{52,53}$ and activate $\mathrm{p} 38$ and JNK, ${ }^{34,54,55}$ all of which are required for IL- 4 production by $\mathrm{CD}^{+}{ }^{+} \mathrm{T}$ cells. ${ }^{48}$ Our data are in agreement with these findings. In contrast, aspirin has also been reported to suppress ERK1/2 activity; ${ }^{46,47}$ however, ERK1/2 was activated by UV or phorbol myristate acetate before treatment with aspirin in these studies. Our data demonstrate unequivocally that aspirin activates ERK1/2, supporting the involvement of ERK1/2 in aspirinmediated IL-4 induction (Figure 3). Overall, aspirin-induced IL-4 production appears to rely on signaling pathways and their subsequent molecular events (see below). Celecoxib can also mobilize these signaling molecules in some epithelial cells. ${ }^{56,57}$ However, this inhibitor did not activate pathways associated with IL-4 expression, at least in the cell types examined in our study. We therefore conclude that the capacity of aspirin to induce IL-4 expression is consistent with its ability to initiate biochemical and molecular processes leading to the induction of IL-4 production.

Our data conflict with a previous report concluding that aspirin inhibits $I L-4$ transcription in phorbol myristate acetate/ionomycin-stimulated peripheral blood $\mathrm{CD}^{+}{ }^{+} \mathrm{T}$ cells, ${ }^{33}$ a result that has not been confirmed to date. Additionally, aspirin has been shown to mediate anti-inflammatory responses by inhibiting numerous signaling molecules,

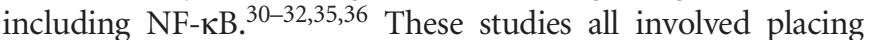
cells under strong inflammatory conditions. However, there are also a few studies demonstrating the proinflammatory effects of aspirin itself, including the upregulation of nuclear NFAT expression $^{58}$ and the activation of NF- $\mathrm{\kappa B} .{ }^{59}$ Thus, aspirin can exert both proinflammatory and anti-inflammatory functions depending on the inflammatory context.

We found that $I L-4$ mRNA and protein levels were significantly higher in aspirin-treated PBMCs from AERD patients compared with that in aspirin-treated PBMCs from ATA patients (Figure 7). This result is consistent with a previous study, in which lysine aspirin induced $\mathrm{Ca}^{2+}$ mobilization in eosinophils isolated from AERD patients. ${ }^{60}$ Furthermore, Steinke et al. ${ }^{61}$ showed that nasal polyps from patients with AERD had significantly elevated IL-4 and interferon- $\gamma$ expression compared with polyps from patients with an aspirin-tolerant disease. However, it is not yet known whether high IL-4 concentrations induced by aspirin elicit the characteristic phenotypes of AERD, including CysLT overproduction/hyperreactivity and reduced $\mathrm{PGE}_{2}$ synthesis. Nonetheless, as our data show that aspirin induces IL-4 production at a much higher level in PBMCs from AERD compared with that in ATA patients, it would be critically informative for the diagnosis of AERD to compare aspirininduced IL-4 production between larger cohorts of patients.

It has been shown that aspirin has both inhibitory and stimulatory effects on notable signaling molecules, especially at high doses. These include NF-kB, ${ }^{30}$ ERK1/2, ${ }^{36}$ STAT6, ${ }^{31,32}$ p38, ${ }^{45}$ and JNK. ${ }^{62}$ These effects are exerted by single- to two-digit millimolar concentrations of aspirin. It has recently been shown that lysine aspirin at $3-10 \mathrm{~mm}$ provokes $\mathrm{Ca}^{2+}$ mobilization and degranulation of eosinophil-derived neurotoxin in peripheral blood eosinophils from AERD patients and in CB eosinophils. ${ }^{60}$ Therefore, the concentrations of aspirin used in this study appear to be comparable to those in most other in vitro studies.

In summary, here, we reveal a previously unrecognized transcriptional target of aspirin, IL-4. Aspirin-induced IL-4 production exploits known biochemical and molecular pathways involved in $I L-4$ transcription. Of particular note, much higher IL-4 levels are produced in aspirin-treated PBMCs from patients with AERD compared with those from patients with ATA. Thus, IL-4 functions as a new inflammatory mediator that might drive AERD pathogenesis.

\section{CONFLICT OF INTEREST}

The authors declare no conflict of interest.

\section{ACKNOWLEDGEMENTS}

This work was supported by a grant from the Korea Healthcare Technology R\&D Project, Ministry of Health, Welfare and Family Affairs and Republic of Korea (HI13C0319). SKK was supported by BK21 Plus, Korea Research Foundation. Whole blood was obtained from the Biobank in Soonchunhyang University, Bucheon Hospital (Republic of Korea) after obtaining written consent from the subjects. We thank Drs Tae Wook Yoo and Woo Sung Lim (Woosung Women's Hospital, Ansan, Republic of Korea) for providing CB.

1 Lee RU, Stevenson DD. Aspirin-exacerbated respiratory disease: evaluation and management. Allergy Asthma Immunol Res 2011; 3: 3-10.

2 Farooque SP, Lee TH. Aspirin-sensitive respiratory disease. Annu Rev Physiol 2009; 71: 465-487.

3 Stevenson DD, Szczeklik A. Clinical and pathologic perspectives on aspirin sensitivity and asthma. J Allergy Clin Immunol 2006; 118: 773-786. 
4 Nasser SM, Pfister R, Christie PE, Sousa AR, Barker J, Schmitz-Schumann $\mathrm{M}$ et al. Inflammatory cell populations in bronchial biopsies from aspirin-sensitive asthmatic subjects. Am J Respir Crit Care Med 1996; 153: 90-96.

5 Sousa AR, Pfister R, Christie PE, Lane SJ, Nasser SM, Schmitz-Schumann $\mathrm{M}$ et al. Enhanced expression of cyclo-oxygenase isoenzyme 2 (COX-2) in asthmatic airways and its cellular distribution in aspirin-sensitive asthma. Thorax 1997; 52: 940-945.

6 Varga EM, Jacobson MR, Masuyama K, Rak S, Till SJ, Darby Y et al. Inflammatory cell populations and cytokine mRNA expression in the masal mucosa in aspirin-sensitive rhinitis. Eur Respir J 1999; 14: 610-615.

7 Antczak A, Montuschi P, Kharitonov S, Gorski P, Barnes PJ. Increased exhaled cysteinyl-leukotrienes and 8-isoprostane in aspirin-induced asthma. Am J Respir Crit Care Med 2012; 166: 301-306.

8 Szczeklik A, Sladek K, Dworski R, Nizankowska E, Soja J, Sheller J et al. Bronchial aspirin challenge causes specific eicosanoid response in aspirin-sensitive asthmatics. Am J Respir Crit Care Med 1996; 154: 1608-1614.

9 Cowburn AS, Sladek K, Soja J, Adamek L, Nizankowska E, Szczeklik A et al. Overexpression of leukotriene C4 synthase in bronchial biopsies from patients with aspirin-intolerant asthma. J Clin Invest 1998; 101: 834-846.

10 Peters-Golden M, Henderson WR Jr. Leukotrienes. N Engl J Med 2007; 357: 1841-1854

11 Laidlaw TM, Kidder MS, Bhattacharyya N, Xing W, Shen S, Milne GL et al. Cysteinyl leukotriene overproduction in aspirin-exacerbated respiratory disease is driven by platelet-adherent leukocytes. Blood 2012; 119: 3790-3798.

12 Szczeklik A, Stevenson DD. Aspirin-induced asthma: advances in pathogenesis and management. J Allergy Clin Immunol 1999; 104: 5-13.

13 Montuschi P, Peters-Golden ML. Leukotriene modifiers for asthma treatment. Clin Exp Allergy 2010; 40: 1732-1741.

14 Szefler SJ, Apter A. Advances in pediatric and adult asthma. J Allergy Clin Imuunol 2005; 115: 470-477.

15 Jang AS, Park JS, Lee JH, Park SW, Kim DJ, Uh ST et al. Asthmatics without rhinitis have more fixed airway obstruction than those with concurrent rhinitis. Allergy Asthma Immunol Res 2010; 2: 108-113.

16 Pauls JD, Simon RA, Daffern PJ, Stevenson DD. Lack of effect of the 5-lipoxygenase inhibitor zileuton in blocking oral aspirin challenges in aspirin-sensitive asthmatics. Ann Allergy Asthma Immunol 2000; 85: 40-45.

17 Stevenson DD, Simon RA, Mathison DA, Christiansen SC. Montelukast is only partially effective in inhibiting aspirin responses in aspirin-sensitive asthmatics. Ann Allergy Asthma Immunol 2000; 85: 477-482.

18 Berges-Gimeno MP, Simon RA, Stevenson DD. The effect of leukotrienemodifier drugs on aspirin-induced asthma and rhinitis reactions. Clin Exp Allergy 2002; 32: 1491-1496.

19 Dahlen SE, Maimstrom K, Nizankowska E, Dahien B, Kuna P, Kowalski M et al. Improvement of aspirin-intolerant asthma by montelukast, a leukotriene antagonist: a randomized, double-blind, placebo-controlled trial. Am J Respir Crit Care Med 2002; 165: 9-14.

20 Ragab S, Parikh A, Darby YC, Scadding GK. An open audit of montelukast, a leukotriene receptor antagonist, in nasal polyposis associated with asthma. Clin Exp Allergy 2001; 31: 1385-1391.

21 Voehringer D, Shinkai K, Locksley RM. Type 2 immunity reflects orchestrated recruitment of cells committed to IL-4 production. Immunity 2004; 20: 267-277.

22 Riechelmann $H$, Deutschle T, Rozsasi A, Keck T, Polzehi D, Burner $H$. Nasal biomarker profiles in acute and chronic rhinosinusitis. Clin Exp Allergy 2005; 35: 1186-1191.

23 Hsieh FH, Lam BK, Penrose JF, Austen KF, Boyce JA. T helper cell type 2 cytokines coordinately regulate immunoglobulin E-dependent cysteinyl leukotriene production by human cord blood-derived mast cells: profound induction of leukotriene $\mathrm{C}(4)$ synthase expression by interleukin 4. J Exp Med 2002; 193: 123-133.

24 Mellor EA, Austen KF, Boyce JA. Cysteinyl leukotrienes and uridine diphosphate induce cytokine generation by human mast cells through an interleukin 4-regulated pathway that is inhibited by leukotriene receptor antagonists. J Exp Med 2002; 195: 583-592.

25 Mellor EA, Frank N, Soler D, Hodge MR, Lora JM, Austen KF et al. Expression of the type 2 receptor for cysteinyl leukotrienes (CysLT2R) by human mast cells: functional distinction from CysLT1R. Proc Natl Acad Sci USA 2003; 100: 11589-11593.

26 Early SB, Barekzi E, Negri J, Hise K, Borish J, Steinke JW. Concordant modulation of cysteinyl leukotriene receptor expression by IL-4 and
IFN-gamma on peripheral immune cells. Am J Respir Cell Mol Biol 2007; 36: 715-720.

27 Steinke JW, Payne SC, Borish L. Interleukin-4 in the generation of the AERD phenotype: implications for molecular mechanisms driving therapeutic benefit of aspirin desensitization. J Allergy 2012; 2012: 1-9.

28 Schleimer RP, Sterbinsky SA, Kaiser J, Bickel CA, Klunk DA, Tomioka K et al. IL-4 induces adherence of human eosinophils and basophils but not neutrophils to endothelium. Association with expression of VCAM-1. J Immunol 1992; 148: 1086-1092.

29 Maier E, Duschl A, Horejs-Hoeck J. STAT6-dependent and -independent mechanisms in Th2 polarization. Eur J Immunol 2012; 42: 2827-2833.

30 Kopp E, Ghosh S. Inhibition of NF-kappa B by sodium salicylate and aspirin. Science 1994; 265: 956-959.

31 Perez-G M, Melo M, Keegan AD, Zamorano J. Aspirin and salicylates inhibit the IL-4- and IL-13-induced activation of STAT6. J Immunol 2002; 168: 1428-1434.

32 Steinke JW, Culp JA, Kropf E, Borish L. Modulation by aspirin of nuclear phospho-signal transducer and activator of transcription 6 expression: possible role in therapeutic benefit associated with aspirin desensitization. J Allergy Clin Immunol 2009; 124: 724-730.

33 Cianferoni A, Schroeder JT, Kim J, Schmidt JW, Lichtenstein LM, Georas SN et al. Selective inhibition of interleukin-4 gene expression in human T cells by aspirin. Blood 2001; 97: 1742-1749.

34 Tegeder I, Pfeilschifter J, Geisslinger G. Cyclooxygenase-independent actions of cyclooxygenase inhibitors. FASEB J 2001; 15: 2057-2072.

35 Dong Z, Huang C, Brown RE, Ma WY. Inhibition of activator protein 1 activity and neoplastic transformation by aspirin. J Biol Chem 1997; 272: 9962-9970.

36 Schwenger P, Skolnik EY, Vilcek J. Inhibition of tumor necrosis factorinduced $\mathrm{p} 42 / \mathrm{p} 44$ mitogen-activated protein kinase activation by sodium salicylate. J Biol Chem 1996; 271: 8089-8094.

37 White AA, Stevenson DD. Does suppression of IL-4 synthesis by aspirin explain the therapeutic benefit of aspirin desensitization treatment? J Allergy Clin Immunol 2010; 126: 745-746.

38 Kim BS, Park SM, Uhm TG, Kang JH, Park JS, Jang AS et al. Effect of single nucleotide polymorphisms within the interleukin-4 promoter on aspirin intolerance in asthmatics and interleukin-4 promoter activity. Pharmacogenet Genomics 2010; 20: 748-758.

39 Kong SK, Kim BS, Uhm TG, Lee W, Lee GR, Park CS et al. Different GATA factors dictate CCR3 transcription in allergic inflammatory cells in a cell type-specific manner. J Immunol 2013; 190: 5747-5756.

40 Uhm TG, Lee SK, Kim BS, Kang JH, Park CS, Rhim TY et al. CpG methylation at GATA elements in the regulatory region of CCR3 positively correlates with CCR3 transcription. Exp Mol Med 2012; 44: 268-280.

41 Burke TF, Casolaro V, Georas SN. Global strategy for asthma management and prevention: GINA executive summary. Biochem Biophys Res Commun 2000; 270: 1016-1023.

42 Bateman ED, Hurd SS, Barnes PJ, Bousquet J, Drazen JM, FitzGerald M et al. Fatty acid binding protein 1 is related with development of aspirin-exacerbated respiratory disease. Eur Respir J 2008; 31: $143-178$.

43 Kim TH, Lee JY, Park JS, Park SW, Jang AS, Lee JY et al. Fatty acid binding protein 1 is related with development of aspirin-exacerbated respiratory disease. PLOS ONE 2011; 6: e22711.

44 Nizankowska-Mogilnicka E, Bochenek G, Mastalerz L, Swierczyńska M, Picado C, Scadding G et al. EAACI/GA22LEN guideline: aspirin provocation tests for diagnosis of aspirin hypersensitivity. Allergy 2007; 62: 1111-1118.

45 Vane JR, Mitchell JA, Appleton I, Tomlinson A, Bishop-Bailey D, Croxtall J et al. Inducible isoforms of cyclooxygenase and nitric-oxide synthase in inflammation. Proc Natl Acad Sci USA 1994; 91: 2046-2050.

46 Huang C, Ma WY, Hanenberger D, Cleary MP, Bowden GT, Dong Z. Inhibition of ultraviolet B-induced activator protein-1 (AP-1) activity by aspirin in AP-1-luciferase transgenic mice. J Biol Chem 1997; 272: 26325-26331.

47 Pillinger $\mathrm{MH}$, Capodici C, Rosenthal P, Kheterpal N, Hanft S, Philips MR et al. Modes of action of aspirin-like drugs: salicylates inhibit erk activation and integrin-dependent neutrophil adhesion. Proc Natl Acad Sci USA 1998; 95: 14540-14545.

48 Li-Weber M, Krammer PH. Regulation of IL4 gene expression by T cells and therapeutic perspectives. Nat Rev Immunol 2003; 3: 534-543.

49 Li-Weber M, Giaisi M, Baumann S, Pálfi K, Krammer PH. NF-kappa B synergizes with NF-AT and NF-IL6 in activation of the IL-4 gene in T cells. Eur J Immunol 2004; 34: 1111-1118. 
50 Hogan PG, Chen L, Nardone J, Rao A. Transcriptional regulation by calcium, calcineurin, and NFAT. Genes Dev 2003; 17: 2205-2232.

51 Weiss DL, Hural J, Tara D, Timmerman LA, Henkel G, Brown MA. Nuclear factor of activated $T$ cells is associated with a mast cell interleukin 4 transcription complex. Mol Cell Biol 1996; 16: 228-235.

52 Gerli R, Paolucci C, Gresele P, Bistoni O, Fiorucci S, Muscat C et al. Salicylates inhibit adhesion and transmigration of $T$ lymphocytes by preventing integrin activation induced by contact with endothelial cells. Blood 1998; 92: 2389-2398.

53 Flescher E, Fossum D, Gray PJ, Fernandes GM, Harper J, Talal N. Aspirin-like drugs prime human T cells. Modulation of intracellular calcium concentrations. J Immunol 1991; 146: 2553-2559.

54 Schwenger P, Alpert D, Skolnik EY, Vilcek J. Cell-type-specific activation of C-Jun N-terminal kinase by salicylates. J Cell Physiol 1999; 179: 109-114.

55 Mifflin RC, Saada JI, Di Mari JF, Valentich JD, Adegboyega PA, Powell DW. Aspirin-mediated COX-2 transcript stabilization via sustained p38 activation in human intestinal myofibroblasts. Mol Pharmacol 2004; 65: 470-478.

56 Shishodia S, Koul D, Aggarwal BB. Cyclooxygenase (COX)-2 inhibitor celecoxib abrogates TNF-induced NF-kappa B activation through inhibition of activation of I kappa B alpha kinase and Akt in human non-small cell lung carcinoma: correlation with suppression of COX-2 synthesis. J Immunol 2004; 173: 2011-2022.

57 Wang ZL, Fan ZQ, Jiang HD, Qu JM. Selective Cox-2 inhibitor celecoxib induces epithelial-mesenchymal transition in human lung cancer cells via activating MEK-ERK signaling. Carcinogenesis 2013; 34: 638-646.

58 Cianferoni A, Massaad M, Feske S, De la Fuente MA, Gallego L, Ramesh N et al. Defective nuclear translocation of nuclear factor of activated $T$ cells and extracellular signal-regulated kinase underlies deficient IL-2 gene expression in Wiskott-Aldrich syndrome. J Allergy Clin Immunol 2005; 116: 1364-1371.

59 Stark LA, Din FV, Zwacka RM, Dunlop MG. Aspirin-induced activation of the NF-kappaB signaling pathway: a novel mechanism for aspirin-mediated apoptosis in colon cancer cells. FASEB J 2001; 15: 1273-1275.

60 Steinke JW, Negri J, Liu L, Payne SC, Borish L. Aspirin activation of eosinophils and mast cells: Implications in the pathogenesis of aspirinexacerbated respiratory disease. J Immunol 2014; 193: 41-47.

61 Steinke JW, Liu L, Huyett P, Negri J, Payne SC, Borish L. Prominent role of IFN- $\gamma$ in patients with aspirin-exacerbated respiratory disease. J Allergy Clin Immunol 2013; 132: 856-865.

62 Schwenger P, Alpert D, Skolnik EY, Vilcek J. Activation of p38 mitogenactivated protein kinase by sodium salicylate leads to inhibition of tumor necrosis factor-induced IkappaB alpha phosphorylation and degradation. Mol Cell Biol 1998; 18: 78-84.

(c) (1)(2) (2) This work is licensed under a Creative Commons Attribution-NonCommercial-ShareAlike $\quad 4.0$

International License. The images or other third party material in this article are included in the article's Creative Commons license, unless indicated otherwise in the credit line; if the material is not included under the Creative Commons license, users will need to obtain permission from the license holder to reproduce the material. To view a copy of this license, visit http://creativecommons.org/licenses/by-nc-sa/4.0/

Supplementary Information accompanies the paper on Experimental \& Molecular Medicine website (http://www.nature.com/emm) 